\title{
Imaginario social de la Educación Física construido desde las "teen series" de televisión españolas
}

\author{
Isaac Pérez López* \\ Enrique Rivera García** \\ Carmen Trigueros Cervantes ${ }^{* * *}$
}

\begin{abstract}
Resumen: Esta investigación indaga sobre el imaginario construido en torno a la Educación Física desde las "teen series" españolas y que toman como referente la vida de un centro educativo. Como estudio fenomenológico, utiliza una metodología cualitativa para analizar la información producida a partir del visionado de las series objeto del estudio (Compañeros; Física o Química y El Internado); la categorización de videos ha sido apoyada por el software NVivo10. Los resultados más relevantes nos muestran una asignatura infravalorada socialmente, anclada en un enfoque mecanicista, con un docente práctico, acrítico y desvalorizado intelectualmente.
\end{abstract}

Palabras clave: Educación Física; análisis cualitativo; conducta del adolescente; medios de comunicación de masas.

\section{INTRODUCCIÓN}

El impacto e influencia que ha alcanzado en la sociedad actual la televisión ha llegado a tal nivel que las "[...] ideas acerca del mundo cada vez tienen más que ver con la forma en que, en el seno de esa cultura de masas, se seleccionan y se exhiben unas u otras informaciones a la vez que se ocultan e ignoran otras" (LOMAS, 2005, p. 49). Dicha circunstancia llega hasta el punto de que, según Montero (2006), existen casos en los que un tema

\footnotetext{
*Departamento de Educación Física. Facultad de Ciencias del Deporte. Universidad de Granada, Granada, España. E-mail: isaacj@ugr.es

**Área de Didáctica de la Expresión Corporal. Facultad de Ciencias de la Educación. Universidad de Granada. Granada, España. E-mail: erivera@ugr.es

***Área de Didáctica de la Expresión Corporal. Facultad de Ciencias de la Educación. Universidad de Granada. Granada, España. E-mail: ctriguer@ugr.es
} 
tratado en un serial de televisión ha conseguido mayores niveles de concienciación social que determinadas campañas de publicidad o informaciones reales sobre el tema en cuestión. De hecho, "[...] los medios de comunicación contribuyen a la formación de las identidades profesionales, así como a los estereotipos en torno a éstas" (RODRÍGUEZ-CAMERO; RODRÍGUEZ-CAMERO; AZAÑÓN-HERNÁNDEZ, 2008, p. 119). Dichos estereotipos constituyen, como han determinado las diversas investigaciones realizadas al efecto, "[...] una imagen generalizada o aceptada comúnmente por un grupo -sobre otras personas o grupos-, que se transfiere en el tiempo, pudiendo adquirir la categoría de verdad indiscutible" (GALÁN, 2007, p. 230).

En este contexto, el público adolescente, e incluso muchos adultos, acaban elevando los estereotipos que se le ofertan a la categoría de verdades absolutas dado que, como señalan RodríguezCamero, Rodríguez-Camero y Azañón-Hernández, (2008, p. 120), "[...] los medios de comunicación, se han legitimado como 'reflejos de la realidad' o 'depositarios de la verdad'", llegando a crear tendencia en la sociedad (MEDRANO, 2005). Estas afirmaciones se refuerzan desde los propios datos de consumo televisivo, que en los años 2008 y 2009 logra su cota más alta, según la TNS Audiencias de medios, situándola en 3 horas y 45 minutos por persona y día. Además, debemos ser conscientes de la escasa o prácticamente nula formación crítica de la sociedad respecto al medio, lo que se traduce en una falta de mediación adecuada en cuanto a límites y enseñanza fílmica, situacional y valorativa de ésta (MEDRANO, 2005).

Desde hace más de una década, según los estudios de Medrano, Palacios y Barandiarán (2007) y Medrano, Aierbe y Palacios (2010), la principal preferencia para la audiencia (fundamentalmente juvenil y adolescente) la constituyen las series de ficción, al margen de ciertos eventos deportivos, como matiza García de Castro (2008). Según recoge este último autor, a raíz de un estudio encargado por Televisión Española, uno de los principales motivos del gran atractivo de estas series se encuentra en que

Movimento, Porto Alegre, v. 20, n. 3, p. 853-873, jul./set. de 2014. 
"[...] la ficción televisiva es un producto de mayor flexibilidad y capacidad de adaptación a las nuevas rutinas y costumbres vitales del espectador" (GARCÍA DE CASTRO, 2008, p. 148). Y dentro de ellas, además, se han puesto de moda una serie de producciones televisivas que recrean la vida de los profesionales que trabajan en el ámbito escolar ("Compañeros", "El Internado", "Física o Química”...). Producciones donde se describe un mundo muy significativo para la población adolescente, que se ha convertido en el personaje estrella de las estrategias televisivas.

Por tanto, partiendo de que los medios no se limitan a reflejar la realidad, sino que en buena medida contribuyen a crearla (GÓMEZ CALDERÓN, 2005), es evidente que existiría una realidad verídica y otra mediática, y aunque la segunda debería ser un reflejo de la verdadera realidad, habitualmente sólo se construye con aquellas partes que más interesan (RODRÍGUEZ-CAMERO; RODRÍGUEZ-CAMERO; AZAÑÓN-HERNÁNDEZ, 2008). En este sentido, Imbert (2008) señala que el modelo televisivo actual da un paso más, y no conforme con construir su propia realidad la transforma en espectáculo.

La Educación Física (EF) no ha quedado al margen de verse reflejada en el espejo de las series televisivas que antes mencionábamos; podríamos decir que el efecto reflejo es doble, por una parte nos permite reconocernos tal y como nos ve un sector significativo de la sociedad $\mathrm{y}$, por otra, la imagen que reflejan ayudan a conformar en el telespectador su percepción sobre la EF. Los estudios sobre esta temática son escasos en España (GALÁN, 2006; GONZÁLEZ-ARÉVALO, 2006; GARCÍAMUÑOZ; FEDELE, 2011), y la trascendencia de estas series en la conformación del imaginario colectivo en torno a la EF importante. Nuestro objetivo lo hemos centrado en describir e interpretar los estereotipos sociales asignados a la asignatura y sus personajes, a través del análisis de las "teen series" más significativas del ámbito español recreadas en contextos escolares y emitidas en horario prime time por televisión.

Movimento, Porto Alegre, v. 20, n. 3, p. 853-873, jul./set. de 2014. 


\section{Metodología}

La investigación realizada se enmarca en un enfoque cualitativo, desde el cual vamos a describir e interpretar la realidad, en este caso ficción, objeto de estudio (GIBB, 2012; RUIZ, 2003). Las "teen series" seleccionadas ocuparon el prime time de la parrilla televisiva desde finales de 1990 hasta el 2011, por lo que nos dan una idea de su alto nivel de aceptación. La base de la investigación la conforman las series: "Compañeros" (1998-2002), "El Internado" (2007-2010) y "Física o Química" (2008-2011), todas ellas emitidas por la cadena privada Antena 3 tv. Otro factor importante para la elección de estas series es que todas ellas cuentan entre sus personajes principales con la figura del docente de EF. En la tabla 1 podemos identificar a los personajes que han sido objeto de análisis. Junto a ellos también hemos analizado a cuatro profesores sustitutos ( 3 mujeres y 1 hombre), que en diferentes momentos de la serie han sustituido a alguno de los personajes principales.

Tabla 1: Temporadas, capítulos y personajes principales analizados

\begin{tabular}{ccccc}
\hline Serie & Temporada & Capítulos & Personajes principales \\
\hline Compañeros & 9 & 107 & Virginia \\
\hline El Internado & 7 & 81 & Pedro & Hugo \\
\hline Física o Química & 7 & 81 & Jonathan & Vaquero \\
\hline
\end{tabular}

Fuente: elaboración propia

Para la realización del análisis, nos hemos apoyado en las pautas marcadas por Galán (2006; 2007), para el estudio y análisis de la ficción televisiva, pero utilizando para ello las prestaciones que nos ofrece el software NVivo10 (TRIGUEROS; RIVERA; TORRE, 2011; VALDEMOROS-SAN EMETERIO, M.A; PONCE-DE-LEÓN-ELIZONDO, A; SANZ-ARAZURI, E., 2011; WILTSHIER, 2011), que nos ha permitido clasificar y categorizar

Movimento, Porto Alegre, v. 20, n. 3, p. 853-873, jul./set. de 2014. 
cada una de las secuencias de vídeo seleccionadas para el análisis en base a los siguientes criterios: serie de procedencia; temporada; capítulo; momento de inicio y finalización de secuencia; personaje de la secuencia y caracterización en la misma desde los tres perfiles definidos: físico, psicológico y sociológico.

Figura 1- Resultado de la Frecuencia de palabras con NVivo10

\begin{tabular}{|c|c|c|c|c|}
\hline & CA Resultados de Consulta de fte & $\mathbf{x}$ & & \\
\hline & Palabea & , & Longtud & Conteo \\
\hline & geogiffica & & 10 & 2 \\
\hline & gestor & & 6 & 1 \\
\hline & gimnasia & & 8 & 70 \\
\hline & global & & 6 & 4 \\
\hline & globales & & 8 & 2 \\
\hline (m) & globalización & & 13 & 1 \\
\hline S Recursos & golfo & & 5 & 1 \\
\hline & gran & & 4 & 1 \\
\hline Nodos & grandes & & 7 & 1 \\
\hline & grupo & & 5 & 1 \\
\hline$\Leftrightarrow$ Clasificaciones & grupos & & 6 & 1 \\
\hline Colecciones & guenta & & 6 & 1 \\
\hline & guian & & 5 & 1 \\
\hline Consultas & ho & & 2 & 1 \\
\hline & habet & & 5 & 1 \\
\hline [D] Informes & haberio & & 7 & 1 \\
\hline & habilldades & & 11 & 4 \\
\hline Modelos & habitankes & & 10 & 1 \\
\hline Farpetas & habituales & & 10 & 4 \\
\hline Carpecas & habría & & 6 & 1 \\
\hline & hace & & 4 & 3 \\
\hline
\end{tabular}

Fuente: elaboración propia

A partir del paso descrito, se ha entrado en un análisis del discurso producido en cada una de las secuencias, siguiendo las pautas marcadas por Strauss y Corbin (2002), focalizando nuestra atención en aquellos tópicos que van emergiendo de forma natural en el discurso y que van a conformar el imaginario creado en torno a la EF. Este primer análisis nos permite realizar una primera categorización inductiva (viva), para pasar en un segundo momento a su reorganización en torno a los tópicos principales presentes. Además, aprovechando las posibilidades que nos ofrece el NVivo, hemos entrado en el análisis de frecuencias de palabras significativas que, inicialmente, nos indican el peso que puede tener el concepto en discurso (figura 1). Fruto de este análisis, hemos generado un mapa conceptual previo que es el que nos guiará por todo el proceso de descripción e interpretación de los hallazgos más significativos (figura 2).

Movimento, Porto Alegre, v. 20, n. 3, p. 853-873, jul./set. de 2014. 
Figura 2- Imaginario Social sobre la EF construido en las series de TV

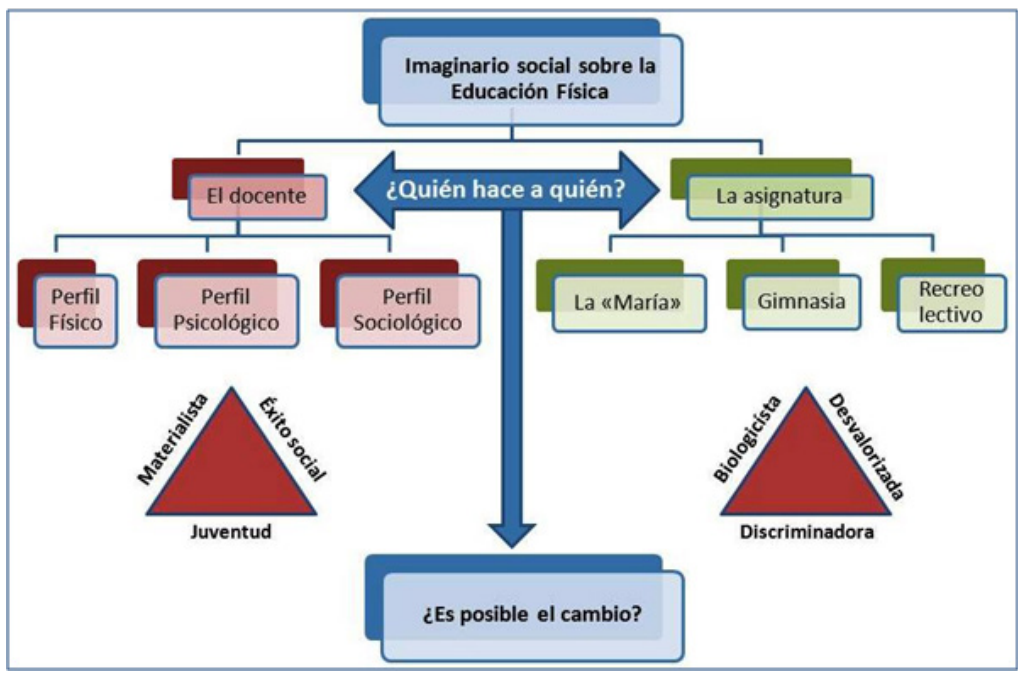

Fuente: elaboración propia

\section{Descripción E INTERPRETACIÓN DE LOS HALLAZgos MÁS SIGNIFICATIVOS}

Nuestra referencia para este análisis va a ser el mapa conceptual (figura 2), construido a partir de los tópicos más representativos que emergen del estudio. Aclarar que este mapa se elabora a partir de la categorización descrita en el apartado anterior. Se establecen dos ejes claves de análisis: por una parte la pregunta sería ¿quién hace a quién?, ¿son los docentes los que definen las líneas o es la inercia de la asignatura la que lo arrastra a reproducir sistemáticamente los tópicos y prácticas existentes?; en segundo lugar, tenemos que reflexionar sobre las posibilidades de cambio, ¿es posible? A grandes rasgos se identifican dos grandes núcleos de tópicos agrupados en torno al docente y la asignatura. Respecto al profesorado aparece una persona joven, de físico cuidado, extrovertido socialmente que busca, y obtiene en la mayoría de los casos, la aceptación social y que está preocupado del hoy, inmerso en un "presentismo" que le aleja de actitudes críticas y de la preocupación por crecer culturalmente. Si miramos a la asignatura,

Movimento, Porto Alegre, v. 20, n. 3, p. 853-873, jul./set. de 2014. 
nos encontramos con una desvaloración tanto social como escolar, con una clara finalidad biologicista que provoca, en la mayoría de los casos, el alejamiento y la animadversión de los menos dotados motrizmente. Es decir, seguimos anclados en la "gimnasia" en la que nos introdujo la dictadura y que treinta años de democracia aún no ha sabido transformar. Entremos en un análisis más detallado de las líneas que acabamos de exponer.

\subsection{Gimnasia no, Educación Física}

Desde el análisis realizado, percibimos la dificultad para desterrar el concepto anticuado y erróneo de "gimnasia" para referirse a la E.F. escolar. Circunstancia ésta que evidencia un gran desconocimiento, o despreocupación, sobre el verdadero significado de dicha asignatura, originando una confusión terminológica con grandes consecuencias para la imagen del área. Desde la frecuencia de palabras realizado a partir de las secuencias seleccionadas se han encontrado un total de 70 referencias (Gráfica 1), donde en algo más de 2 de cada $3(68,6 \%)$ se utiliza el término gimnasia, y solamente en el tercio restante $(31,4 \%)$ el de EF. El uso mayoritario de gimnasia no se produce únicamente en el alumnado, sino también en profesores, directores e, incluso, el propio profesorado de E.F. Circunstancia que, evidentemente, hace un flaco favor al área, puesto que las características y valor formativo que se le atribuye a la gimnasia poco tienen que ver con el de la E.F.

Resulta llamativo que el concepto "Gimnasia" esté más presente en las series más actuales ("El Internado" y "Física o Química") que en "Compañeros", lo que podemos interpretar como un retroceso, aunque también puede ser un simple problema de guionistas. Lo que si queda evidente, es que la EF del periodo democrático, que goza de un currículum multidisciplinar y con el acento puesto en aspectos más de carácter valórico que de rendimiento motriz, aún no ha sido capaz de desbancar, al menos conceptualmente, a la Gimnasia del XIX, que presidió gran parte de los tiempos de actividad física escolar de la España franquista.

Movimento, Porto Alegre, v. 20, n. 3, p. 853-873, jul./set. de 2014. 
Gráfica 1-Frecuencia de uso del término gimnasia y E.F. en las series analizadas

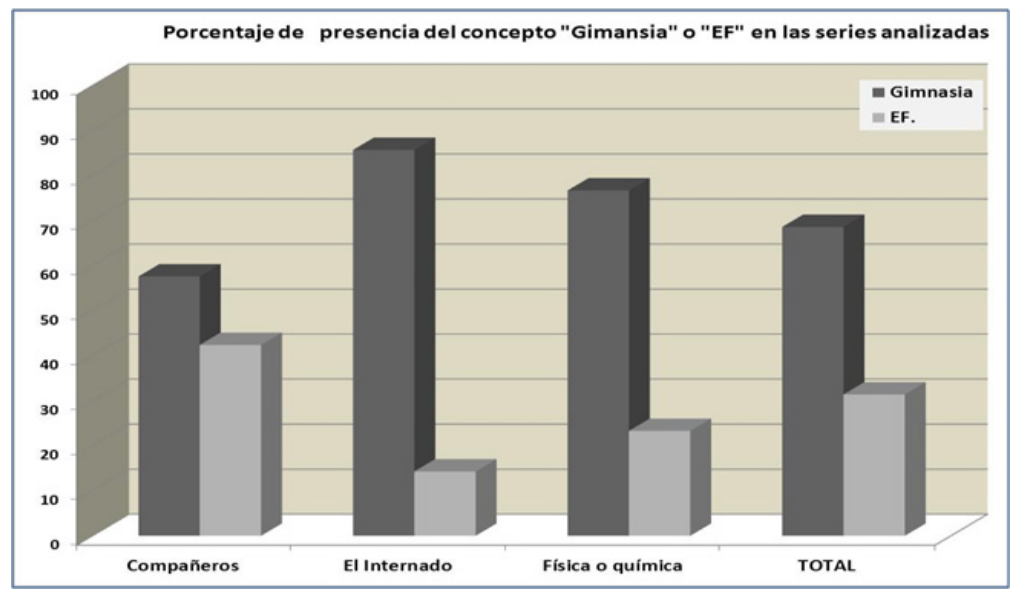

Fuente: elaboración propia

Aún podemos ver cómo los medios de comunicación, prensa, radio, televisión, mantienen el concepto en anuncios de publicidad, noticias sobre el área de EF o en coloquios y entrevistas. Basta recordar como ejemplo el anuncio de un detergente por parte de un famoso jugador de futbol (David Villa), que se transforma por un día en el profe de gimnasia del colegio, para convencer a las madres de que su producto lava más blanco. El problema es el impacto social que tiene y que, de forma inconsciente, refuerza no solo el concepto "gimnasia" sino que, además, identifica la clase con un simple partido de fútbol.

Evidentemente, los guionistas tienen gran parte de responsabilidad, ya que suelen ser personas que han vivido de lleno, o al menos cerca la gimnasia franquista, por lo que es lógico basarse en sus vivencias para dotarla de mayor credibilidad (GONZÁLEZ ARÉVALO, 2006). Además, hay que tener en cuenta que son series dirigidas a un público de todas las edades, por lo que es más sencillo que se identifiquen con una EF con una finalidad de simple mejora funcional, basada en ejercicios analíticos, repetitivos, con formaciones muy rígidas y a golpe de silbato. En este sentido, las 3 series que conforman el grueso de este estudio no son las únicas

Movimento, Porto Alegre, v. 20, n. 3, p. 853-873, jul./set. de 2014. 
en la que se pueden encontrar ejemplos de ello. En uno de los capítulos en el que llega un nuevo profesor de EF, lo primero que hace es poner a los alumnos firmes y en fila para saltar el potro a golpe de silbato, como si se tratara del ejército (Compañeros; 2/06, $\left.6^{\prime} 42^{\prime \prime} / / 9^{\prime} 17^{\prime \prime}\right)^{1}$. De hecho, un alumno acaba teniendo pesadillas con su profesor (vestido con uniforme militar) por su dificultad para saltarlo. Es evidente que esta secuencia está muy alejada de la EF que podemos ver en los centros educativos hoy en día, pero no debemos olvidar que el imaginario social también se construye desde estas imágenes que, como diría Galán (2007), pueden ser transferidas a verdad incuestionable por el espectador al relacionar realidad y ficción.

\subsection{Educación Física; una Asignatura "María"2 CAMino del EXILIO CURRICULAR}

Si entendemos el currículum escolar como la cultura relevante que una sociedad quiere transmitir a sus futuras generaciones de forma intencionada (GRUNDY, 1991), probablemente estemos asistiendo a la agonía de la presencia de la EF en los tiempos lectivos. Cuando entramos en los diálogos de la serie podemos ver cómo se manifiesta esa idea de "maría", a la que antes hacíamos alusión. Se asocia el suspenso en EF con el último nivel de torpeza que puede alcanzar un estudiante "Joder, la tía ésta es una cazurra, catea hasta gimnasia" (Internado; 3/04, 45'51'"//45'53' ). Y en otra ocasión llega a cuestionarse su valor y presencia en el currículum escolar, cuando un alumno le pide a una compañera que modifique en las actas su suspenso en E.F. con el ordenador, y ésta, no muy segura de lo que está haciendo, le pregunta: "recuérdame cómo me has convencido para hacer esto", a lo que él le contesta: "porque los dos pensamos que la gimnasia no debería ser obligatoria"

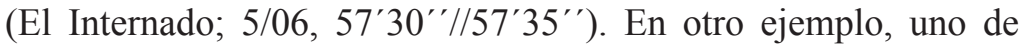

\footnotetext{
${ }^{1}$ Se indica, por este orden: la serie de referencia, el capítulo, la temporada y el tiempo de duración de la secuencia.

EI término "maría" se asigna en España a las asignaturas que se supone se aprueban con poco o ningún esfuerzo. El nombre viene de "las tres marías", que se asocian con la Música, la EF y la Religión.
}

Movimento, Porto Alegre, v. 20, n. 3, p. 853-873, jul./set. de 2014. 
los alumnos protagonista de la serie ante la exigencia del nuevo profesor de EF comenta: "ya no vamos a aprobar ni las cutres" (Compañeros; 2/06, 7'14''//7'16"'). Estos comentarios que van aportando andamiajes a la idea que de la EF se transmite en estas series, explicitan una percepción bastante generalizada de entender la asignatura como un "tiempo de recreo en tiempo escolar", en el que el alumnado (especialmente el de secundaria) cada vez se siente menos cómodo, al ver cómo la asignatura se vuelve más exigente para tratar de igualarse con el resto (LÓPEZ-RODRÍGUEZ, 2011).

El escaso valor curricular que otorgan a la EF los alumnos de las series analizadas es plenamente compartido por el profesorado. Un ejemplo lo encontramos en una de las secuencias de "Compañeros", cuando Sara (una alumna con un gran expediente) suspende E.F. Ante el gran revuelo que origina entre el profesorado esta circunstancia, la directora se reúne con la profesora de E.F., el jefe de estudios y el tutor de la alumna. En un momento de la reunión, ante la presión a la que está siendo sometida la profesora para que apruebe a la citada alumna, ésta le pregunta a uno de ellos por qué no hace él lo mismo con un alumno al que ha suspendido. A lo que la directora, en tono desafiante, responde: "Porque las ciencias son más importantes que la gimnasia. Así de sencillo, y cuanto antes lo asumas, mejor" (Compañeros; 3/14, 43'30'//43'"35' '). Además, uno de los profesores apostilla que "La nota media de Sara va a bajar por algo tan poco importante en su carrera académica como la gimnasia" (Compañeros; 3/14, 37'06'"//37'13"'). Estos diálogos de ficción son frecuentes en los centros, especialmente en aquellos en los que el carácter privado de los mismos coarta la libertad del docente (MORENO-DOÑA et al., 2013).

La única tabla de salvación que se vislumbra para no ser exiliados a los tiempos no lectivos la encontramos, una vez más, en los enfoques biológicos del área, vinculando salud, actividad física y alimentación (JOHNSON; DESHPANDE, 2000; RYE et al., 2008; SALMON et al., 2007). La obesidad, especialmente entre los niños y adolescentes ha tomado carácter de pandemia (GÓMEZ; MARCOS, 2006), al transformar los tiempos de ocio activo en

Movimento, Porto Alegre, v. 20, n. 3, p. 853-873, jul./set. de 2014. 
pasivo. Es el triunfo de las nuevas tecnologías de la comunicación e información sobre la calle, la plazuela, el patio o la pista deportiva (STRASBURGER; JORDAN; DONNERSTEIN, 2010). Ante esta realidad, que casi nadie se atreve a criticar, debiéramos preguntarnos si existen otros caminos por los que debiera transitar la asignatura.

\subsection{EL DOCENTE DE EF. ¿CABEZA?; CUERPO Y EXTREMIDADES}

¿Cómo esbozan las series analizadas al docente de EF? Podríamos contestar que como el complemento perfecto a la asignatura presentada. Lejos de los modelos críticos, se asienta en los principios que sustentan los modelos técnico y práctico, predominando este último sobre el resto (DELGADO, 2000). Diseccionemos la imagen que se transmite y analicemos los perfiles tenidos en cuenta en el análisis. En cuanto al aspecto físico nos presenta un docente (hombre o mujer) entre los 25 y 40 años, que destaca por su atractivo físico, “...un poco simple, pero está bueno" (Física o Química; 1/02, 26'58'"//27'), que como expresa Jonathan a un colega quisieran “... ser algo más que un cuerpo y una cara bonita". Que se erigen en "modelos corporales" para sus alumnos y alumnas, causando su admiración y provocando comentarios como: “... el profe nuevo, lo que no sabe es que está buenísimo” (E1 Internado; 5/02, 12'04"//12'06”), “¡Está buena la nueva!" (Física o Química; 1/06, 11'30"'//11'33"). Solo tenemos una excepción en Pedro, de "El Internado", que con una edad más madura que el resto presenta un aspecto físico menos llamativo. Desde esta filosofía, es probable que la vida útil de un docente de EF no superaría los 45 o 50 años, en el mejor de los casos, por lo que nos encontraríamos ante un profesional con obsolescencia programada.

Si analizamos a los docentes desde el perfil psicológico en el que se encuadran, nos encontramos con profesionales extrovertidos, donde las mujeres aparentan ser más es y, con mayor sensibilidad y empatía hacia los alumnos. Frente a ellas, los profesores destacan

Movimento, Porto Alegre, v. 20, n. 3, p. 853-873, jul./set. de 2014. 
por un mayor pragmatismo, más propio de un temperamento perceptivo, reproduciendo la desigualdad habitual en las series de televisión en la representación de lo femenino y masculino (BELMONTE; GUILLAMÓN, 2008).

En ninguno de los casos sobresalen por su capacidad intelectual o cultura general, salvo Hugo, quien fue un alumno ejemplar durante sus estudios y con grandes calificaciones. Es más, Jonathan y Vaquero se caracterizan por pretender ser (o aparentar) lo que no son, lo que le origina más de un problema con los alumnos. Jonathan suele quedar en evidencia habitualmente con sus compañeros. Por su parte, es curioso como Vaquero, ante el imprevisto de verse como accionista mayoritario del colegio tras la muerte de su padre, agobiado por la responsabilidad reconoce a un amigo: "yo sé que mi padre me dejó el marrón del colegio para demostrar a todo el mundo que él tenía razón y soy un zote" (Física o Química; 5/01, 39'35'"//39'39"').

Desde un perfil sociológico, suelen ser personas solteras, sin hijos e independientes, que viven en soledad o compartiendo piso con otros compañeros de trabajo. La falta de estabilidad en las relaciones es una constante en los personajes analizados, incluyendo la infidelidad en el caso de Pedro, quien mantiene paralelamente dos relaciones con otras dos docentes, Amelia y Elsa, esta última embarazada de su mejor amigo. Son personajes abiertos frente a la sexualidad, en el caso de los hombres, pero no así en el de las mujeres. Y también ellos demuestran una mayor preocupación por su vida personal que profesional, a diferencia de ellas.

En cuanto a la relación que mantienen con sus alumnos suele ser muy cercana, hasta el punto de provocar situaciones que desvalorizan la asignatura y le otorgan el papel de "maría" y "recreo lectivo" al que hacíamos referencia anteriormente. La presentación de Vaquero en su primer día de clase constituye un excelente ejemplo de lo que acabamos de decir:

"Profesor: Como es nuestra primera clase, os voy a hacer un regalo. Hoy mandáis vosotros, hacemos lo que digáis [Evidentemente los alumnos no dan

Movimento, Porto Alegre, v. 20, n. 3, p. 853-873, jul./set. de 2014. 
crédito a lo que están escuchando y, tras varias muestras de incredulidad, uno de ellos le pregunta]

Alumno: “En serio podemos decir lo que queramos?".

Profesor: "Claro", responde él, en plan profesor enrollado.

Alumno: "Pues entonces nada".

Profesor: “¿Nada?"

Alumno: "Claro, aquí en la sombrita, una cervecita, unos pitis, ¿no?’'Ante la sorpresa de sus

alumnos contesta]:

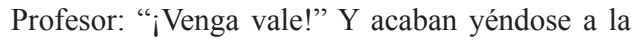
cafetería del centro"

(Física o Química; 4/04, 30'39"'//31'22')

Este "buen rollito" entre este profesor y el grupo de alumnos va aún más lejos cuando les pregunta si les importa que comparta con ellos el botellón que están organizando para celebrar el cumpleaños de uno de ellos. Ante el asombro de éstos les dice: "A ver chaval, entérate, el botellón lo inventó mi generación; y tenéis que verme a mí de botellón, soy el puto rey" (Física o Química; 4/08, 46'22'"//46'29'"). Pero no contentos con esto, los guionistas, llevando aún más al límite la imagen del docente, le asignan el papel de proveedor de las bebidas alcohólicas que se van a consumir en la fiesta de un grupo de adolescentes menores de edad. Si nos quedaba la esperanza de la tabla de salvación que supone ser "los guardianes de la salud", mucho nos tememos que acaba de saltar por los aires. Somos conscientes de la necesidad de los guionistas de construir personajes fácilmente reconocibles por el público, que faciliten el proceso de identificación (GALÁN, 2006) y que susciten su interés, lo que puede ser el motivo que justifique la imagen que de él se presenta. Qué duda cabe que el profesorado de E.F. puede encarnar, por ejemplo, el estereotipo

Movimento, Porto Alegre, v. 20, n. 3, p. 853-873, jul./set. de 2014. 
de hombre joven, atractivo y con un cuerpo trabajado físicamente (por las características definitorias de la formación de éstos), que atraiga la atención de un target muy determinado y beneficioso para los intereses comerciales de este tipo de producciones. Pero esta caracterización o, mejor dicho, caricatura, evidentemente no resulta nada positiva ni aceptable, pues pone en entredicho la capacitación y profesionalidad del colectivo.

¿Cómo se muestra al profesor de EF en las series respecto al resto del colectivo docente? Fundamentalmente como una persona que hace incompatible el culto al cuerpo con el culto a la cultura y formación del espíritu. Tenemos múltiples ejemplos que podrían ilustrar lo dicho, como el que aparece en la serie "Compañeros", en el que aprovechando una charla de Fernando Savater, el centro pone en marcha una iniciativa para animar a la lectura. A1 comentar la responsable de la actividad que ningún profesor se ha interesado por los libros del autor, uno de ellos espeta (no falto de prejuicios): "Qué dices a eso Virginia, aunque seas profesora de EF ¿no crees que como educadora no te vendría nada mal leer alguno?" (Compañeros; 3/11, 39'//39'07' '). Algo parecido sucede en "Física o Química" cuando una profesora llega a la biblioteca y al ver a Jonathan comenta con ironía: "El profesor de EF en la biblioteca. Debería sacarte una foto y enseñársela a los alumnos" (Física o Química; 1/02, 21'59'"//22'06' '). El eterno tópico de ver como incompatible la fuerza o la belleza con la inteligencia tendría sentido en el marco de una EF del siglo XIX, pero hoy día, donde el concepto de cuerpo ha superado la dualidad platónica, la EF y el docente que la imparte debieran estar alejados del enfoque cuerpomáquina, centrado en exclusiva en obtener el máximo rendimiento al cuerpo biológico, buscando propuestas educativas integrales que involucren al individuo en su globalidad, como ser pensante, que se emociona y se mueve para comunicarse consigo mismo, los otros y el contexto en el que se desenvuelve.

El resultado final de todo este proceso es la discriminación profesional que sufren los profesores de EF respecto al resto de colegas. Hecho que, si bien se ha logrado solventar en estos

Movimento, Porto Alegre, v. 20, n. 3, p. 853-873, jul./set. de 2014. 
últimos años (en los años ochenta, en España, los docentes de EF, a igualdad de horas, ganaban un $30 \%$ menos que el resto del profesorado), aún está latente en el imaginario colectivo la creencia que muestran los personajes de la serie cuando, en situación de huelga de profesores (solicitando aumento salarial), el director le comenta al jefe de estudios "iQue quieren cobrar más, dicen; todos, hasta el de gimnasia!" [y el jefe de estudios responde] ¿También? ¡Hay que tener morro!” (Compañeros; 5/03, 38'21'"//38'-27'”).

¿Es posible el cambio? Siempre es posible. Evidentemente debe partir de una actitud crítica del profesorado del área, tomando conciencia de la realidad que tiene frente a él. Investigaciones recientes perciben un docente de EF más preocupado por el desarrollo de valores traducidos en estilos de vida saludables, fomento de actitudes de respeto, tolerancia y cooperación, que en mejorar el rendimiento motor de sus alumnos (HERNÁNDEZÁLVAREZ et al., 2010; SÁENZ-LÓPEZ; SICILIA; MANZANO, 2010). A pesar de todo, se sigue percibiendo un área dispersa respecto a su desarrollo, provocado en parte por una formación inicial descontextualizada, excesivamente mecanicistas y lejos de la realidad social (RONSPIES, 2011; SMITH; SCHMIDT, 2012); así como por un currículum excesivamente abierto y poco definido, que deja al arbitrio del docente su implementación, lo que genera una falta de consistencia y uniformidad que debilita la imagen de la asignatura frente al resto de los agentes educativos (VALVERDE, 2008). Esto nos está llevando hacia una clara depreciación del área, más si cabe, que poco a poco está perdiendo su estatus curricular en beneficio de las áreas tradicionales, lo que nos puede abocar a terminar fuera del tiempo lectivo y pasar a espacios extracurriculares (CZYZ; TORIOLA, 2012). Aún estamos a tiempo, pero hay que trazar las líneas maestras de la asignatura y dotarlas de valor social. Un eje está claro: la salud, pero junto a él debemos comenzar a diseñar una EF preocupada por la transmisión de valores que origine ciudadanos críticos. Pensamos que esto no es incompatible, al contrario, engrana perfectamente con la idea de ofrecer a los estudiantes un nivel de competencia y compromiso motriz lo suficientemente sólido que lo adhiera a una práctica sistemática y responsable de actividad física.

Movimento, Porto Alegre, v. 20, n. 3, p. 853-873, jul./set. de 2014. 


\section{Conclusiones}

Los resultados obtenidos evidencian el escaso valor social otorgado en las series analizadas a la EF por parte del alumnado, profesorado y gestores de los centros escolares. Se muestra una asignatura poco rigurosa, muy alejada de las funciones que le otorga el currículum y centrada en el desarrollo de las capacidades y habilidades motrices de los estudiantes. Los docentes se identifican con personas de baja formación intelectual, más preocupados de su aspecto externo que de dar respuesta a las demandas del área. Extrovertidos, cercanos y con gran empatía hacia sus alumnos, transforman la clase generalmente en espacio lúdico, donde el aprendizaje tiene poca cabida y la única preocupación se centra en el hacer por el hacer.

El modelo mecanicista potenciado desde la figura del docente práctico que nos muestra el estudio, no se aleja en demasía del imaginario construido en torno a la EF por parte de un gran sector de la sociedad, que ve en la asignatura un espacio más recreativo que educativo. La responsabilidad, como profesionales del área, es transformar esta imagen por otra que, desde la reflexión y la crítica, lleve al estudiante a saber diferenciar entre la ficción y la realidad, entre una EF mecanicista, de otra preocupada por dar respuesta a las demandas sociales respecto al conocimiento, respeto y cuidado que requiere nuestro cuerpo visto como globalidad indisoluble, que debe atender a todas las facetas de la persona, tanto física, como afectiva, psicológica y social.

Por los expuesto es preciso dar respuesta a aspectos básicos como el de aumentar la competencia televisiva del alumnado (PÉREZ-TORNERO, 1997; MEDRANO, 2008) desde un trabajo de análisis, reflexión y crítica en el aula de EF. Hay que ver a la televisión no como competidora, sino como fuente de aprendizaje (MEDRANO, CORTÉS; PALACIOS, 2007), aprovechando el potencial de significatividad que tiene para la sociedad. Además, en futuros estudios debemos indagar las causas que han llevado a la construcción del imaginario percibido desde las series objeto de estudio.

Movimento, Porto Alegre, v. 20, n. 3, p. 853-873, jul./set. de 2014. 
PE's social imaginary built from "teen series" on Spanish TV

Abstract: This research investigates the imaginary about Physical Education built in Spanish TV "teen series", based on life at an educational center. As a phenomenological study, it uses a qualitative methodology to analyze the information produced by viewing the series that were the focus of the study (Compañeros; Física o Química; and El Internado). Videos were classified with NVivo10 software. The main results show a socially undervalued subject, based on a mechanistic approach, with a practical, uncritical and intellectually devalued teacher.

Keywords: Physical Education; qualitative analysis; adolescent behavior; mass media.

Imaginário social Educação Física construído a partir da "teen série" da televisão espanhola.

Resumo: Esta pesquisa investiga o imaginário construído em torno da Educação Física de séries teen da televisão espanhola que tomam como referência a vida de uma escola. Como um estudo fenomenológico, utiliza uma metodologia qualitativa para analisar as informações produzidas a partir da visualização das séries em estudo (Compañeros, Física o Química e El Internado). A categorização de vídeos foi apoiada pelo software NVivo10. Os principais resultados mostram uma disciplina socialmente desvalorizada, enraizada em uma abordagem mecanicista, com um professor prático, anticrítico e intelectualmente desvalorizado.

Palavras-chave: Educação Física; análise qualitativa; comportamento do adolescente; meios de comunicação de massa. 


\section{REFERENCIAS}

BELMONTE-AROCHA, J.; GUILLAMÓN-CARRASCO, S. Co-educar la mirada contra los estereotipos de género en TV. Comunicar, Huelva, n. 31, p. 115-120, 2008.

CZYZ, S. H.; TORIOLA, A. L. Polish Children's Perception and Understanding of Physical Education and School Sports. Journal of Teaching in Physical Education, Champaign, n. 31, p. 39-55, 2012.

DELGADO, M.A. Nuevo papel del profesorado y de la enseñanza de la Educación Física: de la práctica a la investigación. En: PÁRRAGA, J.A.; ZAGALAZ, M. L.. Reflexiones sobre Educación Física y deporte en la edad escolar. Jaén: Universidad de Jaén, 2000.

GALÁN, E. Construcción de género y ficción televisiva en España. Comunicar, Huelva, n. 28, p. 229-236, 2007.

GALÁN, E. Personajes, estereotipos y representaciones sociales: una propuesta de estudio y análisis de la ficción televisiva. ECO-PÓS, Río de Janeiro, v. 9, n. 1, p. 58-81, 2006.

GARCÍA DE CASTRO, M. Los movimientos de renovación en las series televisivas españolas. Comunicar, Huelva, n. 30, p. 147-153, 2008.

GARCÍA-MUÑOZ, N.; FEDELE, M. Las series televisivas juveniles: tramas y conflictos en una "teen series". Comunicar, Huelva, v. 19, n. 37, p. 133-140, 2013.

GIBBS, G. El análisis de datos cualitativos en investigación cualitativa. Madrid: Morata, 2012

GÓMEZ CALDERÓN, B.J. Disfunciones de la Socialización a través de los Medios de Comunicación. Razón y Palabra, Monterrey, n. 44, 2005. Disponible en: http:// www.razonypalabra.org.mx/anteriores/n44/bgomez.html. Acceso en: 5 jun. 2013.

GÓMEZ, S.; MARCOS, A. Intervención integral en la obesidad del adolescente. Revista de Medicina de la Universidad de Navarra, Pamplona, v. 50, n.4, p. 23-25, 2006.

GONZÁLEZ ARÉVALO, C. La educación física en la televisión: "Cuéntame cómo pasó”. Tándem, Barcelona, n. 21, p. 28-35, 2006.

GRUNDY, S. Producto o praxis del currículum. Madrid: Morata, 1991.

HERNÁNDEZ-ÁLVAREZ, J. L.; VELÁZQUEZ-BUENDÍA， R.; MARTÍNEZGORROÑO, M.E.; DÍAZ DEL CUETO, M. Creencias y perspectivas docentes

Movimento, Porto Alegre, v. 20, n. 3, p. 853-873, jul./set. de 2014. 
Imaginario social de la Educación Física construido desde ...

sobre objetivos curriculares y factores determinantes de actividad física. Revista Internacional de Medicina y Ciencias de la Actividad Física y el Deporte, Madrid, v. 10, n. 38, p. 336-355, 2010.

IMBERT, G. El transformismo televisivo: pos televisión e imaginarios sociales. Madrid: Cátedra, 2008.

JOHNSON, J.; DESHPANDE, C.. Health Education and Physical Education: disciplines preparing students as productive, healthy citizens for the challenges of the 21st century. Journal of School Health, Hoboken, v. 70, n. 2, p. 66-68, 2000.

LOMAS, C. Comunicación y educación. Cuadernos de Pedagogía, Las Rozas, n. 343, p. 48-52, 2005

LÓPEZ-RODRÍGUEZ, M. Educación Física alternativa. Barcelona: INDE, 2011.

MEDRANO, C. ¿Se puede favorecer el aprendizaje de valores a través de las narraciones televisivas? Revista de Educación (Madrid), n. 338, p. 245-270, 2005.

MEDRANO, C. Televisión y educación: del entretenimiento al aprendizaje. Teoría de la Educación, Salamanca, n. 20, p. 205-224. 2008

MEDRANO, C.; AIERBE, A.; PALACIOS, S. El perfil de consumo televisivo en adolescentes, jóvenes y adultos: implicaciones para la educación. Revista de Educación (Madrid), n. 352, p. 545-566,. 2010.

MEDRANO, C.; CORTÉS, P.A.; PALACIOS, S. La televisión y el desarrollo de valores. Revista de Educación (Madrid), n. 342, p. 307-328, 2007.

MEDRANO, C.; PALACIOS, S.; BARANDIARÁN, A.. Los hábitos y preferencias televisivas en jóvenes y adolescentes: un estudio realizado en el País Vasco. Revista Latina de Comunicación Social, La Laguna, n. 62. 2007. Disponible en: http://www.ull.es/publicaciones/latina/200702Medrano_S_yotros.htm. Acceso en: 2 jun. 2013.

MONTERO, Y. Televisión, valores y adolescentes. Barcelona: Gedisa, 2006.

MORENO-DOÑA et al. La educación física chilena: un modelo tecnocrático de la enseñanza y desvalorización del colectivo docente. Tandem, Barcelona, n. 42 p. 7-17, 2013.

PÉREZ TORNERO, J.M. Educación en televisión. En: AGUADED, : J.I. (Comp.). La otra mirada de la tele: propuestas para un consumo inteligente de la televisión. Sevilla: Consejería de Trabajo e Industria, 1997. p. 23-28.

RODRÍGUEZ-CAMERO, M.L.; RODRÍGUEZ-CAMERO N.; AZAÑÓNHERNÁNDEZ, R.. La construcción mediática de la Enfermería. Index de

Movimento, Porto Alegre, v. 20, n. 3, p. 853-873, jul./set. de 2014. 
enfermería: información bibliográfica, investigación y humanidades, v. 17, n. 2, p. 119-123, 2008.

RONSPIES, S. Who wants to be a physical education teacher? A case study of a non-traditional undergratuate student in a physical education teacher education program. The Qualitative Report, Fort Lauderdale, v. 16, n. 6, p. 1669-1687, 2011.

RUIZ, J. I. Metodología de la investigación cualitativa. Bilbao: Universidad de Deusto, 2003.

RYE, J.A.; O'HARA TOMPKINS, N.; ECK, R.; NEAL, W.A. Promoting youth physical activity and healthy weight through schools. West Virginia Medical Journal, Charleston, v. 104, n.2, p. 12-15, 2008.

SÁENZ-LÓPEZ, P.; SICILIA, A.; MANZANO, J.I. La opinión del profesorado sobre la enseñanza de la educación física en función del género. Revista Internacional de Medicina y Ciencias de la Actividad Física y el Deporte, Madrid, v. 10, n. 37, p. 167-180, 2010.

SALMON, J.; BOOTH, M.L.; PHONGSAVAN, P.; MURPHY, N.; TIMPERIO, A. Promoting physical activity participation among children and adolescents. Epidemiologic Reviews, Oxford, n. 29, p. 144-159, 2007.

SMITH, M. A.; SCHMIDT K. Teachers are making a difference: Understanding the influence of favorite teachers. The Qualitative Report, Fort Lauderdale, v.17, n. 36 , p. 1-25, 2012.

STRASBURGER, V.; JORDAN, A.; DONNERSTEIN, E. Health effects of media on children adolescents. Pediatrics, Elk Grove Village, v. 125, n.4, p. 756-767, 2010.

STRAUSS, A.; CORBIN, J. Bases de la investigación cualitativa: técnicas y procedimientos para desarrollar la teoría fundamentada. Colombia: Universidad de Antioquia, 2002.

TRIGUEROS, C.; RIVERA, E.; TORRE, E.. El Chat como estrategia para fomentar el aprendizaje cooperativo. Una investigación en el Prácticum de Magisterio Profesorado. Revista de Currículum y Formación de Profesorado, Granada, n. 15, 2011. Disponible en: http://www.redalyc.org/articulo.oa?id=56717469014. Acceso en: 7 sept. 2013.

VALDEMOROS-SAN EMETERIO, M.A; PONCE-DE-LEÓN-ELIZONDO, A.; SANZARAZURI, E. Fundamentos en el manejo del Nvivo9 como herramienta al servicio de estudios cualitativos. Contextos Educativos, Logroño, n. 14, p. 11-29, 2011.

VALVERDE, J. Valoración de la asignatura de Educación Física y su relación con los niveles de actividad física habitual en adolescentes escolarizados de la Región de Murcia. Tesis Doctoral, Universidad de Murcia, curso 2008, pp. 450

Movimento, Porto Alegre, v. 20, n. 3, p. 853-873, jul./set. de 2014. 
Imaginario social de la Educación Física construido desde ...

WILTSHIER, F. Researching With NVivo. Forum Qualitative Sozialforschung/ Forum: Qualitative Social Research, v. 12, n. 1, 2011. Disponible en: http://www. qualitative-research.net/index.php/fqs/article/view/1628/3146. Acceso en: 5 sept. 2012.

Endereço para correspondência:

Isaac Pérez López

Facultad de CC. del Deporte

Universidad de Granada

Carretera de Alfacar $\mathrm{s} / \mathrm{n}$

18071-Granada (España)

Recebido em: 22.09.2013

Aprovado em: 14.03.2014

Movimento, Porto Alegre, v. 20, n. 3, p. 853-873, jul./set. de 2014. 